\title{
CHANGES IN TOTAL PHENOL CONTENT AND ANTIOXIDANT ACTIVITY OF GREEK TABLE OLIVE CULTIVAR AMFISSIS DURING MATURATION
}

\author{
NIKOLAOS GOUGOULIAS ${ }^{a}$, LIVIU GIURGIULESCU ${ }^{\mathrm{b}^{*}}$, \\ IOANNIS VAGELAS ${ }^{a}$, ELENI WOGIATZI ${ }^{a}$, \\ MARIA-NEKTARIA NTALLA ${ }^{c}$
}

\begin{abstract}
The Amfissis cultivar olive fruits grown in the region of Larissa, central Greece, were studied for the changes in total polyphenol content, phenolic fractions and antioxidant capacity during maturation period (four months). It has been established that the total phenol content and antioxidant capacity, change in broad ranges depending on the ripening stage of fruits. The content of total phenols in the Amfissis cultivar during

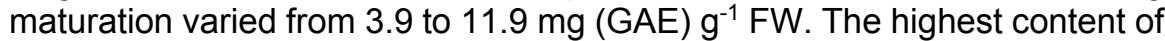
total phenols has been found in the harvest stage (December). The content

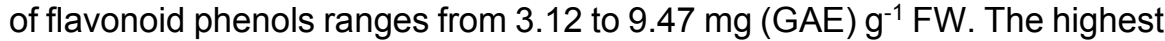
content of flavonoid phenols was determined the time period of the harvesting. The content of non-flavonoid phenols during ripening of olive fruit ranges from 0.78 to $2.43 \mathrm{mg}$ (GAE) $\mathrm{g}^{-1} \mathrm{FW}$. The highest content of NFP was determined the time period of the harvesting (black color). The inhibition concentration $\left(\mathrm{IC}_{50}\right)$ of extract during maturation of the olive fruit in all stages ranges from (735 to 130) $\mathrm{mg} / \mathrm{l}$. The lowest inhibition concentration (highest antioxidant capacity) was observed in the collection stage of the olive fruits. The obtained results have a direct impact on the harvesting date of the table cultivar Amfissis, influencing the sensory properties and the quality of the olive fruit.
\end{abstract}

Keywords: Antioxidant activity FRAP; Olives, Amfissis; Total phenols

a Department of Agronomy Technology, Technological Educational Institute of Thessaly, 41110 Larissa, Greece.

b Department of Chemistry and Biology, Technical University of Cluj Napoca, North Universitary Center of Baia Mare, 430122 Baia-Mare, Romania.

c Department of Computer Science and Engineering, Data Analysis, Technological Educational Institute of Thessaly, 41110 Larissa, Greece.

*Correspondence author: giurgiulescu@gmail.com 


\section{INTRODUCTION}

The fruits are natural reservoir of phenolic compounds and natural antioxidants [1-3]. Olea europaea $L$. is a tree widely cultivated in the Mediterranean area for oil production and for table olives production. Table olives are a traditional Greek product, important component of the Mediterranean diet. Olive fruits are rich in flavonoids, secoiridoids, phenolic acids and phenolic alcohols [47] which exercise high antioxidant activity. Olives cultivar Amfissis are used usually as table olives and to a lesser degree for oil production.

Phenolic compounds influence the sensory properties of the olive fruits. Oleuropein is a phenolic compound from olives responsible for their bitterness [8-10]. The inclusion of table olive in a diet reduces the risk of cardiovascular and some cancer diseases [11-12].

Important changes in phenolic content and antioxidant activity during fruits development was reported [3]. The concentration of oleuropein in the olive fruit decreases with development and maturation of fruit $[9,13]$. The changes in phenolic composition during the maturation of olive fruits are due to hydrolysis of glycosides, oxidation and polymerization of phenolic compounds [14-15].

The aim of this study was the determination of phenolic content and antioxidant activity, in different stages of maturation of Amfissis cultivar fruits grown on the region Sykourio, Larissa, Greece.

\section{RESULTS AND DISCUSSIONS}

Soil samples collected from olive orchard were analyzed for inorganic nutrient element ( $\mathrm{N}, \mathrm{P}, \mathrm{K}, \mathrm{Mn}, \mathrm{Zn}$ and $\mathrm{Cu}$ ) and organic matter content. The soil was a Sandy Loam (SL), with high content in organic matter and nutrients (Table 1).

Figure 1 shows that the concentration of total phenols increased

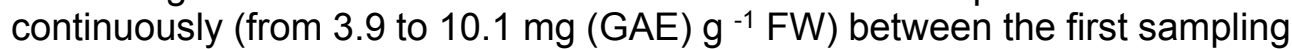
in August (green color fruits) until the time of the fourth sampling in October (reddish-purple color fruits). Then, during ripening between fourth (reddishpurple color) and fifth sampling (purple-black color), the concentration of total phenols showed a stagnation. However, in the last phase of maturity, corresponding to the period between of the purple-black color and of the black color (harvest season), the concentration of total phenols increased

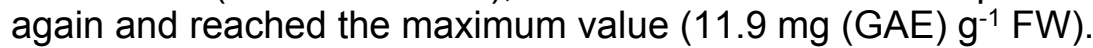

To the same conclusions arrived some researchers which studied the change in the total phenolic content during ripening for some olive fruits from Tunisia [16]. Contrary, decrease of the content total phenolic during ripening 
of olive fruits for some cultivars of Italy observed by [14, 17-19]. In addition, decrease total phenols during ripening for some cultivars of Australian observed by [20]. These differences in the variability of total phenols likely due to the different cultivars, in soil and climatic conditions of each region.

Table 1. Chemical properties of soils from olive orchard

\begin{tabular}{|l|c|c|}
\hline \multirow{2}{*}{ Soil properties } & \multicolumn{2}{|c|}{ Soil depth } \\
\cline { 2 - 3 } & $\mathbf{( 0 - 3 0 )} \mathbf{~ c m}$ & $\mathbf{( 3 0 - 6 0 )} \mathbf{~ c m}$ \\
\hline Texture & Sandy Loam & Sandy Loam \\
\hline $\mathrm{pH}(1: 5)$ & $7.72 \pm 0.31$ & $7.68 \pm 0.31$ \\
\hline $\mathrm{EC}(1: 5), \mathrm{dS} \mathrm{m}^{-1}$ & $0.48 \pm 0.03$ & $0.41 \pm 0.03$ \\
\hline $\mathrm{CaCO}(\%)$ & $6.67 \pm 0.34$ & $11.52 \pm 0.58$ \\
\hline Organic matter $(\%)$ & $2.42 \pm 0.12$ & $1.63 \pm 0.08$ \\
\hline N-inorganic $\left(\mathrm{mg} \mathrm{kg}^{-1}\right)$ & $174.3 \pm 9.68$ & $110.8 \pm 6.16$ \\
\hline K-exchangeable $\left.\mathrm{mg} \mathrm{kg}^{-1}\right)$ & $328.4 \pm 14.29$ & $214.2 \pm 9.87$ \\
\hline $\mathrm{P}$-Olsen $\left(\mathrm{mg} \mathrm{kg}^{-1}\right)$ & $20.8 \pm 1.39$ & $12.4 \pm 0.95$ \\
\hline Cu-DTPA $\left(\mathrm{mg} \mathrm{kg}^{-1}\right)$ & $2.43 \pm 0.22$ & $1.84 \pm 0.15$ \\
\hline Zn-DTPA $\left(\mathrm{mg} \mathrm{kg}^{-1}\right)$ & $4.67 \pm 0.31$ & $2.34 \pm 0.18$ \\
\hline Mn-DTPA $\left(\mathrm{mg} \mathrm{kg}^{-1}\right)$ & $7.43 \pm 0.68$ & $3.78 \pm 0.32$ \\
\hline
\end{tabular}

Data represent average and SE deviation, $(n)=4$.

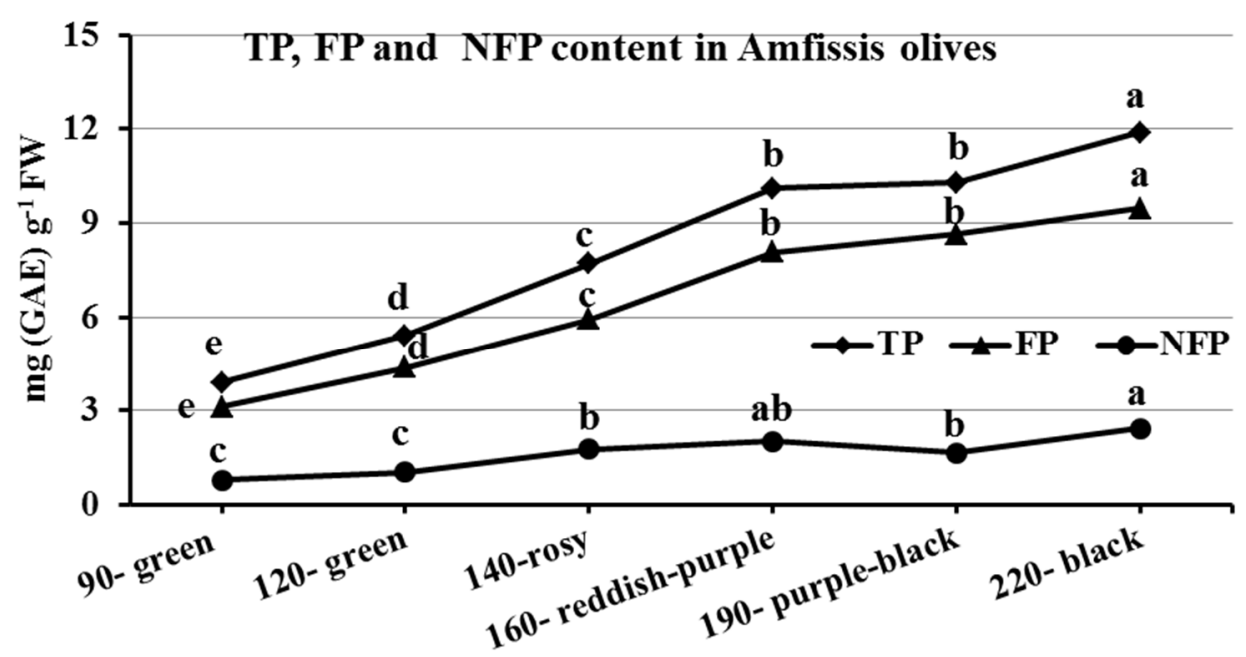

Days from the start of flowering and color of the olive fruit

Figure 1. Changes of total phenol (TP) content, flavonoid phenols (FP) and non-flavonoid phenols (NFP) during maturation of the olive cultivar Amfissis at 90; 120; 140; 160; 190 and 220 days from start of flowering, respectively. Characteristics labeled with the same letter do not differ significantly according to the Tukey's test $(P=0.05)$. 
The variation of the content of flavonoid phenols during ripening of olive fruit was similar to that of total phenols. The content of flavonoid phenols

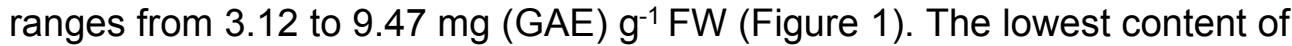
FP was determined the time period of the first sampling (green color), and the highest the time period of the harvesting (black color). The FP content in the olive fruit during the second sampling (green color) constitutes $80.90 \%$ of TP amount, whereas during the third sampling (rosy color) it is lower and reached $77.01 \%$.

The flavonoid phenols (FP) cover a great number of phenolic compounds in the olive fruits, from which prevail the fractions of flavones and flavonols, and exhibit different functions. The content flavones (luteolin, luteolin 7-O-glucoside, apigenin) and flavonols (rutin and quercetin) showing different changes during ripening of olive fruit [13].

The content of non-flavonoid phenols during ripening of olive fruit

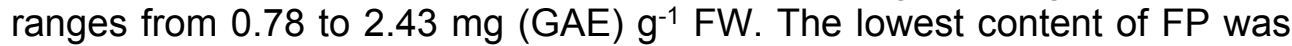
determined the time period of the first and second sampling (green color fruits), and the highest the time period of the harvesting (black color fruits) (Figure 1).

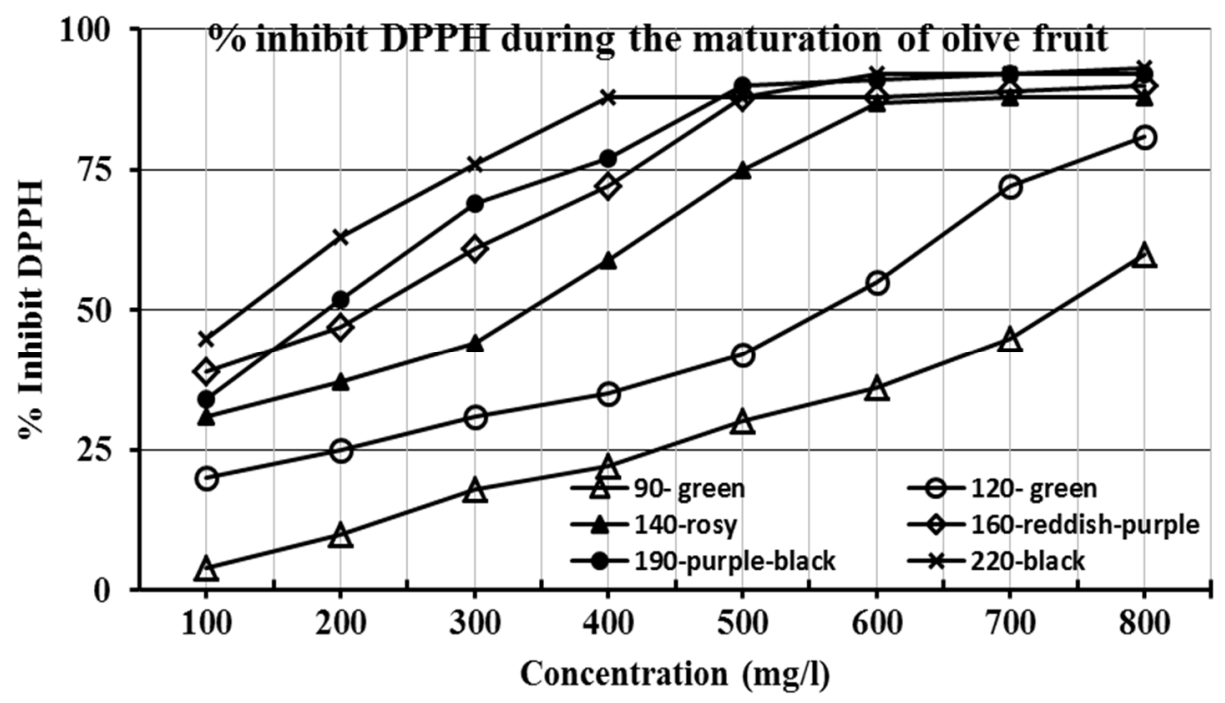

Figure 2. Inhibition percentage DPPH in different concentrations of the extract of samples, during maturation of the olive cultivar Amfissis. 90; 120; 140; 160; 190 and 220 days from start of flowering, respectively. Data represent average, $(n)=4$. 
The scavenging effect of Amfissis olives was also examined using different concentrations of extracts in $80 \%$ methanol (Figure 2). The results are expressed as percentage of the absorbance decrease of DPPH・ solution in the presence of different concentrations of extracts to the absorbance of $\mathrm{DPPH} \cdot$ solution.

From the Figure 2 we can observe that the increase of inhibition percentage $\mathrm{DPPH} \bullet$ is function of increasing concentration of the extract, for all phases of maturation.

The concentration of the extract required to reduce the absorbance of solution DPPH $50 \%$, constitutes the inhibition concentration $\left(\mathrm{IC}_{50}\right)$. The lowest inhibition concentration $\left(\mathrm{IC}_{50}\right)$ corresponds in the highest antioxidant capacity.

Figure 3 shows that the inhibition concentration $\left(\mathrm{IC}_{50}\right)$ of extract during maturation of the olive fruit in all stages ranges from (735 to 130) $\mathrm{mg} / \mathrm{l}$. The lowest inhibition concentration (highest antioxidant capacity) was observed in the collection stage of the olive fruits (black color). The correlation between the inhibition concentration $\left(\mathrm{IC}_{50}\right)$ of the extracts during maturation of the olive fruit and the contents of TP was high, with correlation coefficient $\left(r^{2}\right)$ equal to: 0.972 .

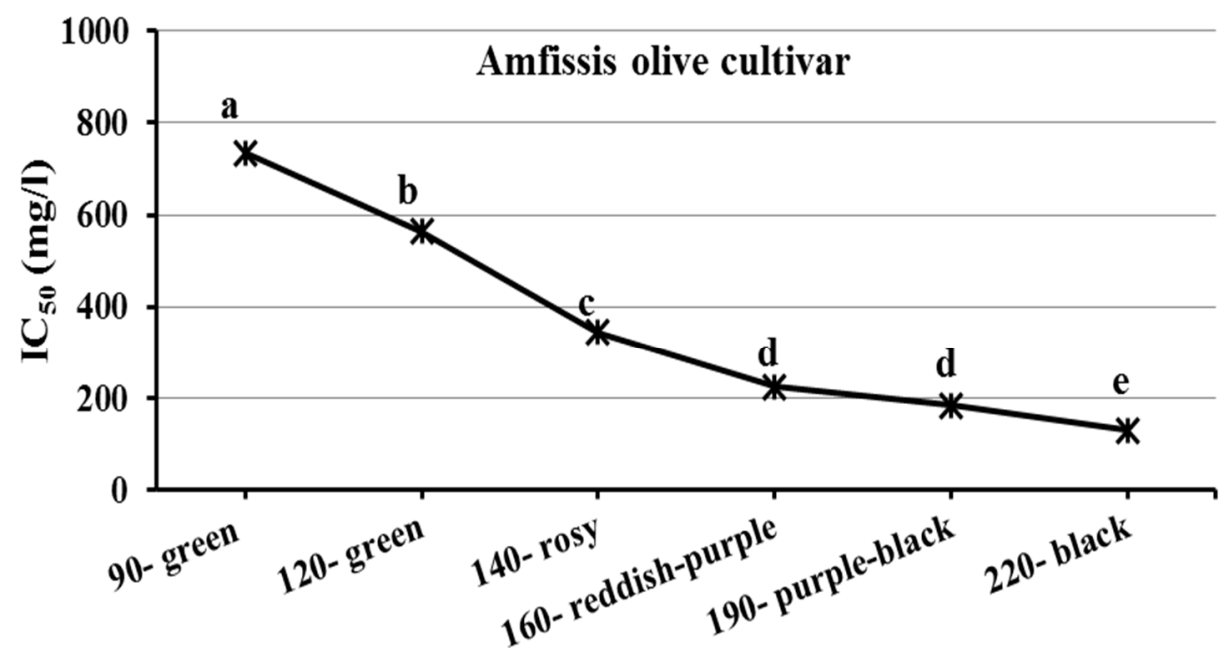

Days from the start of flowering and color of the olive fruit

Figure 3. Antioxidant capacity expressed by median inhibition concentration $\left(\mathrm{IC}_{50}\right)$ during maturation of the olive cultivar Amfissis. At 90, 120, 140, 160, 190 and 220 days from start of flowering, respectively. Each characteristic of the graph labeled with the same letter do not differ significantly according to the Tukey's test $(P=0.05)$. 
Our results are in agreement with the data obtained by other authors which reported decrease of value $\left(\mathrm{IC}_{50}\right)$ during maturation of the olive fruit [21]. These values show that the Amfissis olives have highest antioxidant capacity during maturation from some olives cultivars of Tunisia [21]. Contrary, increase of the value $\left(\mathrm{IC}_{50}\right)$ during maturation of the olive fruit observed by other authors [19]. These differences in the antioxidant capacity of the olive fruit during maturation, due in the quantitative composition of polyphenols and in structure of individual compounds, as a result of the cultivar and climatic factors $[13,22]$.

Each characteristic of the graph with the same letter do not differ significantly according to the Tukey's test $(P=0.05)$.

\section{CONCLUSIONS}

Flavonoids, non-flavonoids, total phenols content and antioxidant capacity of the table olive Amfissis vary with stages maturation, demonstrating the importance of behavior of the Amfissis cultivar. Contrary with most olive varieties, the Amfissis cultivar in the region Larissa, presents the highest total phenolic compounds content and antioxidant activity at the harvest stage (10 December).

The obtained results have a direct impact on the harvesting date of the table cultivar Amfissis, influencing the sensory properties and the quality of the olive fruit.

\section{EXPERIMENTAL SECTION}

\section{Experimental}

The study was carried out in the olive orchard Papadoulis in an area located in region Sykourio, Larissa, Greece, (latitude $39^{\circ} 43^{\prime} 30 " \mathrm{~N}$, longitude $22^{\circ} 44^{\prime} 30 " E, 270 \mathrm{~m}$ altitude), during the $2015-2016$ season. The climate in the area is Mediterranean, with cold rainy winters, average $(5-7)^{\circ} \mathrm{C}$, dry hot summers, average $(25-28)^{\circ} \mathrm{C}$ and average annual precipitation $432 \mathrm{~mm}$. In the olive orchard, the Amfissis cultivar grown, 1970 the planting took place with $7 \mathrm{~m}$ distance tree from tree and $7.5 \mathrm{~m}$ distance line from line. $50 \mathrm{~kg}$ manure corresponding to $1.10 \mathrm{~kg}$ Nitrogen, $0.95 \mathrm{~kg}$ Potassium, $0.35 \mathrm{~kg}$ Phosphorus and $11.5 \mathrm{~kg}$ Organic matter per tree added, and $2000 \mathrm{~m} 3$ irrigation water per hectare added. 
Olives samples were collected from the beginning of development and at different stages of maturation of olive Amfissis, where are observed changes in fruit color with the appearance of the green color (1 August, 90 days from start of flowering), green color (120 days from start of flowering), of the rosy color (140 days from start of flowering), of the reddish purple color (160 days from start of flowering), of the purple-black color (190 days from start of flowering), and black color (220 days from start of flowering). Two trees were chosen, and were sampled of olive fruits half kilogram with four replicates from each tree, from all the orientations and without type of disease.

\section{Preparation of the methanol extracts}

The flesh was separated from the kernel and $100 \mathrm{~g}$ of flesh for each treatment were subjected to freeze drying for further extraction and determination of humidity. The dry mass was crushed and stored in clean bottles in refrigeration [23]. Two $\mathrm{g}$ of dry sample was extracted two times with $50 \mathrm{~mL}$ of $80 \%$ aqueous methanol for $24 \mathrm{~h}$ at $150 \mathrm{rpm}$, the methanolic extracts were combined and washed two times with $25 \mathrm{~mL}$-hexane in order to eliminate the oil of the methanolic extract [24]. The separation of the phases was performed with separating funnels. Subsequently the methanolic extract was evaporated under nitrogen, and the residue was dissolved in $50 \mathrm{~mL}$ of $80 \%$ aqueous methanol, stored in clean bottles in refrigeration in the dark until its use.

\section{Methods of analyses}

Soil was analyzed using the following methods which are referred by Page (1982) [25].

Organic matter was analyzed by chemical oxidation with $1 \mathrm{~mol} \mathrm{~L}^{-1}$ $\mathrm{K}_{2} \mathrm{Cr}_{2} \mathrm{O}_{7}$ and titration of the remaining reagent with $0.5 \mathrm{~mol} \mathrm{~L}^{-1} \mathrm{FeSO}_{4}$.

Inorganic nitrogen was extracted with $0.5 \mathrm{~mol} \mathrm{~L}^{-1} \mathrm{CaCl}_{2}$ and estimated by distillation in the presence of $\mathrm{MgO}$ and Devarda's alloy, respectively. Available $\mathrm{P}$ forms (Olsen $\mathrm{P}$ ) was extracted with $0.5 \mathrm{~mol} \mathrm{~L}^{-1} \mathrm{NaHCO}_{3}$ and measured by spectroscopy. Exchangeable form of potassium was extracted with $1 \mathrm{~mol} \mathrm{~L}^{-1}$ $\mathrm{CH}_{3} \mathrm{COONH}_{4}$ and measured by flame Photometer (Essex, UK).

Available forms of $\mathrm{Mn}, \mathrm{Zn}$, and $\mathrm{Cu}$ were extracted with DTPA (diethylene triamine pentaacetic acid $0.005 \mathrm{~mol} \mathrm{~L}^{-1}+\mathrm{CaCl}_{2} 0.01 \mathrm{~mol} \mathrm{~L}^{-1}+$ triethanolamine $\left.0.1 \mathrm{~mol} \mathrm{~L}^{-1}\right)$ and measured by atomic absorption. The samples were analyzed by Atomic Absorption (Spectroscopy Varian Spectra AA 10 plus, Victoria, Australia), with the use of flame and air-acetylene mixture [26]. 
Electrical conductivity $(\mathrm{EC})$ and $\mathrm{pH}$ measured in the extract (1 part soil : 5 parts $\mathrm{H}_{2} \mathrm{O}$ ).

Determination of total polyphenolics (TP). Total polyphenolic content was determined with the Folin-Ciocalteu (F.-C.) reagent according to the method by [27] using the microvariant proposed by [28] and the results were expressed as gallic acid equivalent (GAE) in $\mathrm{mg} \mathrm{g}^{-1}$ fresh weight.

Nonflavonoid phenols (NFP). The content of NFP was determined with the F.-C. reagent after removing the flavonoid phenols (FP) with formaldehyde according to the method by [29] and was expressed as gallic acid equivalent (GAE) in $\mathrm{mg} \mathrm{g}^{-1}$ fresh weight.

Flavonoid phenols (FP). Flavonoid phenols were determined as a difference between the content of total phenols (TP) and nonflavonoid phenols (NFP). Their amount was evaluated as gallic acid equivalent in $\mathrm{mg} \mathrm{g}^{-1}$ fresh weight.

Determination of antiradical activity (DPPH•). The antiradical activity of the methanol extracts was determined according to the method by [30] using the stable free radical 2,2'-diphenyl-1-picrylhydrazyl (DPPH•). The antiradical activity was expressed through $\mathrm{IC}_{50}$ (Inhibition concentration, $\mathrm{mg} / \mathrm{l}$ ), which expresses the concentration of the extract required to reduce the absorbance of solution DPPH $50 \%$. The absorbance reduction calculated according to the formula (1):

\% Inhibit DPPH= (Absorbance ${ }_{D P P H}$ - Absorbance simple) / Absorbance ${ }_{\text {DPPH }}$ X 100. (1)

The concentration was found from the graph of inhibition percentage DPPH with different concentrations of samples.

\section{Statistical analysis}

Data were analyzed using the MINITAB [31] statistical package. The experiment had four replications. Analysis of variance was used to assess treatment effects. Mean separation was made using Tukey's test when significant differences $(P=0.05)$ between treatments were found.

\section{REFERENCES}

1. N. Gougoulias, Oxidation Communications, 2014, 37 (3), 713-721.

2. N. Gougoulias, P. Vyrlas, L. Giurgiulescu, D. Kalfountzos, F. Eugenia, Carpathian Journal of Food Science and Technology, 2015, 7(4), 119-125. 
3. N, Gougoulias, A. Papachatzis, I. Vagelas, L. Giurgiulescu, A. Karaboula, D. Kalfountzos, Studia UBB Chemia,2016, LXI, 4, 295 - 303.

4. D. Boskou, F. Visioli, Metabolic and technological aspects, 2003, 161-169.

5. M. Bouaziz, R.J. Grayer, M.S. Simmonds, M. Damak, S. Sayadi, Journal of agricultural and food chemistry, 2005,53(2), 236-241.

6. A. Dağdelen, G. Tümen, M.M. Özcan, E. Dündar, Food chemistry, 2013, 136(1), 41-45.

7. S. Silva, L. Gomes, F. Leitao, A.V. Coelho, L.V. Boas, Food Science and Technology International, 2006, 12(5), 385-395.

8. M. Brenes, L. Rejano, P. Garcia, A.H. Sanchez, A. Garrido, Journal of Agricultural and Food Chemistry, 1995, 43(10), 2702-2706.

9. M. Esti, L. Cinquanta, E. La Notte, Journal of Agricultural and Food Chemistry, 1998, 46(1), 32-35.

10. F. Visioli, S. Bellosta, C. Galli, Life sciences, 1998, 62(6), 541-546.

11. R.W. Owen, R. Haubner, G. Würtele, W.E. Hull, B. Spiegelhalder, H. Bartsch,. European Journal of Cancer Prevention, 2004,13(4), 319-326.

12. E. Tripoli, M. Giammanco, G. Tabacchi, D. Di Majo, S. Giammanco, M. La Guardia, Nutrition research reviews, 2005, 18(01), 98-112.

13. M. Bouaziz, M. Chamkha, S. Sayadi, Journal of agricultural and food chemistry, 2004, 52(17), 5476-5481.

14. R.Briante, M. Patumi, S. Limongelli, F. Febbraio, C. Vaccaro, A. Di Salle, F. La Cara, R. Nucci, Plant Science, 2002, 162(5), 791-798.

15. D. Ryan, M. Antolovich, P. Prenzler, K. Robards, S. Lavee, Scientia Horticulturae, 2002, 92(2), 147-176.

16. M. Bouaziz, H. Jemai, W. Khabou, S. Sayadi, Journal of the Science of Food and Agriculture, 2010, 90(10), 1750-1758.

17. R. Fernandez-Orozco, M. Roca, B. Gandul-Rojas, L. Gallardo-Guerrero, Journal of Food Composition and Analysis, 2011, 24(6), 858-864.

18. G. Menz, F. Vriesekoop, Physical and chemical changes during the maturation of Gordal Sevillana olives (Olea europaea L., cv. Gordal Sevillana). Journal of agricultural and food chemistry, 2010, 58(8), 4934-4938.

19. J. R. Morelló, M. P. Romero, M. J. Motilva, Journal of agricultural and food chemistry, 2004, 52(19), 6002-6009.

20. D. Ryan, K. Robards, S. Lavee, Changes in phenolic content of olive during maturation. International journal of food science \& technology, 1999,34(3), 265-274.

21. N. Damak, M. Bouaziz, M. Ayadi, S. Sayadi, M. Damak, Journal of agricultural and food chemistry, 2008, 56(5), 1560-1566.

22. A. Petridis, I. Therios, G. Samouris, HortScience, 2012, 47(3), 339-342.

23. G. Boskou, F.N. Salta, S. Chrysostomou, A. Mylona, A. Chiou, N.K. Andrikopoulos, Food Chemistry, 2006, 94(4), 558-564.

24. G. Rigane, R.B. Salem, S. Sayadi, M. Bouaziz, Journal of food science, 2011, 76(7), C965-C973.

25. M. Varian, Flama Atomic Absorption Spectroscopy. Analytical Methods. Varian Australia. Publ. N0: 85-100009-00, 1989. 
26. A. L. Page, Methods of soil analysis. Part 2. Chemical and microbiological properties. American Society of Agronomy, Soil Science Society of America, 1982.

27. V.L. Singleton, J.A. Rossi, American journal of Enology and Viticulture, 1965, 16(3), 144-158.

28. B. Baderschneider, D. Luthria, A.L. Waterhouse, P. Winterhalter, VITIS-Journal of Grapevine Research, 2015, 38(3), 127-131.

29. T. E. Kramling, V. L. Singleton, American Journal of Enology and Viticulture, 1969, 20(2), 86-92.

30. W. Brand-Williams, M.E. Cuvelier, C.L.W.T. Berset, Use of a Free Radical Method to Evaluate Antioxidant Activity. LWT- Food Science and Technology, 1995, 28(1), 25-30.

31. B.F. Ryan, B.L. Joiner, J.D. Cryer MINITAB Handbook: Updated for release 14, 5th edition, 2005. 